\title{
Unique TLR9 Activation by Helicobacter pylori Depends on the cag T4SS, But Not on VirD2 Relaxases or VirD4 Coupling Proteins
}

\author{
Nicole Tegtmeyer ${ }^{1} \cdot$ Bodo Linz $^{1} \cdot$ Yoshio Yamaoka $^{2} \cdot$ Steffen Backert ${ }^{1}$
}

Received: 22 October 2021 / Accepted: 15 February 2022 / Published online: 3 March 2022

(c) The Author(s) 2022

\begin{abstract}
The genomes of the gastric bacterial pathogen Helicobacter pylori harbor multiple type-IV secretion systems (T4SSs). Here we analyzed components of three T4SSs, the cytotoxin-associated genes (cag) T4SS, TFS3 and TFS4. The cag T4SS delivers the effector protein CagA and the LPS-metabolite ADP-heptose into gastric epithelial cells, which plays a pivotal role in chronic infection and development of gastric disease. In addition, the cag T4SS was reported to facilitate conjugative transport of chromosomal bacterial DNA into the host cell cytoplasm, where injected DNA activates intracellular toll-like receptor 9 (TLR9) and triggers anti-inflammatory signaling. Canonical DNA-delivering T4SSs in a variety of bacteria are composed of 11 VirB proteins (VirB1-11) which assemble and engage VirD2 relaxase and VirD4 coupling proteins that mediate DNA processing and guiding of the covalently bound DNA through the T4SS channel. Nevertheless, the role of the latter components in $H$. pylori is unclear. Here, we utilized isogenic knockout mutants of various virB (virB9 and virB10, corresponding to $\operatorname{cag} X$ and $\operatorname{cag} Y$ ), virD2 (rlxl and $r l x 2)$, virD4 (cag5, traGl/2) and $x e r D$ recombinase genes in H. pylori laboratory strain P12 and studied their role in TLR9 activation by reporter assays. While inactivation of the structural cag T4SS genes $\operatorname{cag} X$ and $\operatorname{cag} Y$ abolished TLR9 activation, the deletion of $r l x 1, r l x 2$, cag5, traG or $x e r D$ genes had no effect. The latter mutants activated TLR9 similar to wild-type bacteria, suggesting the presence of a unique non-canonical T4SSdependent mechanism of TLR9 stimulation by $H$. pylori that is not mediated by VirD2, VirD4 and XerD proteins. These findings were confirmed by the analysis of TLR9 activation by $H$. pylori strains of worldwide origin that possess different sets of T4SS genes. The exact mechanism of TLR9 activation should be explored in future studies.
\end{abstract}

\section{Introduction}

Helicobacter pylori represents a Gram-negative bacterium that colonizes the human stomach. H. pylori infection is common in approximately $50 \%$ of the world's population. While infected patients typically exhibit mild, often asymptomatic chronic gastritis, a subset of patients can develop severe gastric diseases including mucosa-associated lymphoid tissue (MALT) lymphoma, peptic ulceration and gastric adenocarcinoma (reviewed by [1,2]). Gastric cancer represents an eminent cancer type in humans and comprises about one million new patients annually, accounting for

Steffen Backert

Steffen.Backert@fau.de

1 Department of Biology, Chair of Microbiology, FriedrichAlexander-Universität Erlangen-Nürnberg, Staudtstr. 5, 91058 Erlangen, Germany

2 Department of Environmental and Preventive Medicine, Oita University Faculty of Medicine, Yufu, Japan approximately 769,000 deaths in 2020 alone [3]. Owing to these numbers, gastric cancer incidence and mortality rates worldwide rank on position five and four, respectively. The clinical consequences of $H$. pylori infections are affected by numerous key components comprising the host genetic susceptibility, the genotype of the bacteria, various environmental determinants, the diet and microbiota (reviewed by $[1,2])$. Host genetic biomarkers, among others, comprise single-nucleotide polymorphisms in various genes coding for multiple cyto- and chemokines (for example IL-1 $\beta$, IFN$\gamma$, TNF, IL-2, IL-6, IL-8, and IL-10) as well as immune receptors (e.g., NOD1, NOD2, TLR2, TLR4, TLR5, and TLR9) (reviewed by [1, 2, 4]). Studies using animal models such as the Mongolian gerbils pinpointed that $H$. pylori infection and the expression of certain virulence genes are the primary trigger for the development of gastric carcinogenesis (reviewed by [1, 2]).

Worldwide $H$. pylori strains from different continents are genetically highly diverse [5]. During the long co-evolution with its human host, which lasted for over 100,000 years [6], 
various type-IV secretion systems (T4SSs) were acquired and/or evolved, each of which with specific functions (reviewed by [7, 8]). These T4SSs are molecular transport systems that assemble in the inner and outer membranes of many bacteria and are frequently associated with a protruding pilus [9]. Typically, many canonical T4SSs comprise 11 structural protein subunits, called VirB1 to VirB11 (according to the nomenclature of the prototypical T4SS from Agrobacterium tumefaciens), the coupling protein VirD4/ TraG and a DNA processing enzyme (relaxase VirD2). In particular, VirB2-VirB11 and VirD4/TraG are obligatory for effector molecule delivery [10]. According to common categorization, the T4SS functions include (i) the transfer of conjugative and other mobile DNA elements, (ii) the release of DNA into the environment, (iii) the uptake of extracellular DNA, (iv) the transport of effector proteins into the supernatant, as well as (v) the direct injection of effector proteins into the cytoplasm of the host cell. In fact, $H$. pylori encodes up to four different T4SSs: (i) the cytotoxin-associated genes T4SS (cag T4SS), (ii) the ComB apparatus, (iii) a third T4SS called TFS3 and (iv) a fourth T4SS called TFS4 (reviewed by $[8,11]$ ). The cag T4SS mediates the transport of the CagA effector protein into host cells, which is followed by tyrosine phosphorylation by host cell kinases $[8,12]$. In addition, ADP-heptose [13], peptidoglycan [14] and chromosomal DNA $[15,16]$ were also described as substrates translocated into target cells. In contrast, the ComB system facilitates uptake and transport of extracellular DNA into the bacterium [17]. TFS3 as well as TFS4 supposedly represent conjugational DNA transfer systems, which is supported by the discovery of two VirD2-like relaxase enzymes, Rlx1 and Rlx2 [18-20], two VirD4-like coupling proteins (TraG1/2) [18, 19], putative oriT (origin of transfer) sequences detected near the TFS3 and TFS4 genes [8, 20], and tyrosine recombinase (XerD) with recognition sites [21]. In addition, TFS3 might deliver the effector protein CtkA, a putative cell-translocating kinase, into target cells [22-24].

The cag T4SS, which is present in so-called type-I strains (or cag-positive strains), but being absent in type-II isolates (or cag-negative strains), contains about 32 genes encoding the described VirB1-VirB11 homologs, VirD4 along with multiple cag-specific proteins [25-28]. Electron microscopic experiments visualized the $\mathrm{cag}$ T4SS core complex, including the Cag3, CagM, CagT, CagX, and CagY proteins [29, 30]. Besides the effects described above, the cag T4SS was found to activate integrins [12, 31-34] and two toll-like receptors, TLR5 $[35,36]$ and TLR9 $[15,16]$. Interestingly, TLR9 activation was reported to proceed through translocated chromosomal DNA mediated by the cag T4SS, but the exact DNA substrate, oriT and mechanism are yet unknown. TLR9 represents an endosome-associated receptor of the innate immune system that detects hypo-methylated cytidine phosphate guanosine $(\mathrm{CpG})$ oligodinucleotides that are typical for bacterial DNA (reviewed in [37-39]). Stimulation of TLR9 appears to occur in a contact-dependent manner between $H$. pylori and host cells, and requires the structural T4SS proteins CagC (VirB2), CagE (VirB3-VirB4), CagL (VirB5), CagT (VirB7), CagX (VirB9), CagY (VirB10), and the Cag-specific components $\mathrm{CagM}, \mathrm{CagV}$ and $\mathrm{Cag} 3$ [15, 16]. However, DNA transfer mediated by canonical T4SSs commonly requires additional factors, including DNA processing enzymes such as VirD2 relaxases and VirD4 (TraG) coupling proteins (reviewed in $[9,10]$ ). Such VirD2 relaxase enzymes are not encoded in the cag T4SS, but are present in the TFS3 and TFS4 systems as described above. While these DNA processing enzymes are essential for DNA transfer in a variety of bacteria, their importance in $H$. pylori is unclear. We hypothesized that the VirD2, VirD4/TraG and XerD enzymes might be interchangeable among the various H. pylori T4SSs. Thus, in this research we examined the proposed involvement of relaxases Rlx 1 and Rlx 2 and DNA coupling proteins VirD4 and TraG as well as recombinase XerD in chromosomal DNA transfer-mediated TLR9 activation by $H$. pylori.

\section{Materials and Methods}

\section{T4SS Genetic Analysis}

The genome of $H$. pylori strain P12 (Genbank accession number CP001217.1) was subjected to pairwise BLASTn comparisons against the genomes of strains 26695 (NC_000915.1), N6 (VAPN00000000.1), G27 (NC_011333.1), HPAG1 (NC_008086.1), PMSS 1 (CP018823.1), NCTC11637 (NZ_LS483488.1), B128 (NZ_CP024951.1), 7.13 (NZ_CP024953.1), J166 (NZ_CP007603.1), TN2 wt (NZ_AP019730.1), India7 (CP002331.1), Cuz20 (CP002076.1), Shi470 (CP001072.2), Gambia94/24 (CP002332.1), and SouthAfrica7 (NC_017361.1), followed by visual examination in the Artemis Comparison Tool ACT [40]. The nucleotide sequences of the cag T4SS (cagPAI, about $37 \mathrm{~kb}$ ), TFS3 region $(29 \mathrm{~kb}$ ) and TFS4 region $(40 \mathrm{~kb})$ were extracted from the genome of strain P12. Subsequently performed pairwise tBLASTx comparisons were visualized and analyzed in ACT. Gene synteny was compared to published data $[11,26]$. In addition, the inferred protein sequences were extracted and compared in pairwise BLASTp searches, and their inferred function was validated in an NCBI Conserved Domain search.

\section{Human HEK293-TLR5 Reporter Cells and AGS Cell Line}

HEK293 cells (ATCC \#CRL-1573) are derived from embryonic kidney. TLR9 activation was studied using 
HEK293 cells stably transfected with human TLR9/ $\mathrm{NF}-\kappa \mathrm{B} /$ secreted embryonic alkaline phosphatase (SEAP) reporter (HEK-Blue-hTLR9, TLR9 ${ }^{+}$). HEK-Blue-Null cells (parental) were used as a negative control (InvivoGen, San Diego/USA; https://www.invivogen.com/hekblue-htlr9) $[15,16]$. These two cell lines were grown in DMEM (Dulbecco's Modified Eagle Medium) enriched with $110 \mathrm{mg} / \mathrm{L}$ sodium pyruvate, $4.5 \mathrm{~g} / \mathrm{L}$ D-glucose, $4 \mathrm{mM}$ L-glutamine, and $10 \%$ fetal calf serum (FCS) (Thermo Fisher Scientific, Massachusetts, USA). AGS cells (ATCC \#CRL-1739), a gastric epithelial adenocarcinoma cell line, were cultivated in RPMI-1640 medium supplemented with 10\% FCS (Thermo Fisher Scientific, Massachusetts, USA). All three cell lines were subcultured in $75 \mathrm{~cm}^{2}$ tissue culture flasks. To all culture media a $1 \%$ antimycotic and antibiotic solution was added (Sigma-Aldrich) during longterm propagation. In addition, the HEK293 cell medium contained $10 \mu \mathrm{g} / \mathrm{mL}$ blasticidin (InvivoGen) to maintain the integrated hTLR9 plasmid and $100 \mathrm{mg} / \mathrm{mL}$ zeocin to maintain the SEAP plasmid. Before infection, the cells were washed, resuspended in fresh medium without antibiotics, and seeded into 12-well plates (Greiner-Bio-One, Frickenhausen, Germany). Cultivation of cell monolayers was accomplished at 70-80\% confluency [41]. In all experiments, the cells were infected with bacteria at a multiplicity of infection (MOI) of 25 for $24 \mathrm{~h}$. The uninfected cells (mock control) were incubated with the same volume of Brain Heart Infusion (BHI) medium.

\section{Cultivation and Mutagenesis of Bacteria and Infection Experiments}

A list of all used strains and isogenic $H$. pylori mutants is provided in Table S1. The mutants were commonly created by insertion of gene cassettes containing a chloramphenicol or kanamycin resistance gene, respectively, using established protocols. Mutants were confirmed by PCR and Sanger sequencing. Where possible, loss of protein expression was confirmed by Western blotting [42, 43]. The individual $H$. pylori strains were grown on GC agar plates enriched with $10 \%$ horse serum (PAN-Biotech $\mathrm{GmbH}$, Aidenbach, Germany), trimethoprim $(5 \mu \mathrm{g} / \mathrm{mL})$, nystatin $(1 \mu \mathrm{g} / \mathrm{mL})$ and vancomycin $(10 \mu \mathrm{g} / \mathrm{mL})$. For selection, $H$. pylori mutants were cultivated on media with $8 \mu \mathrm{g} /$ $\mathrm{mL}$ kanamycin or $4 \mu \mathrm{g} / \mathrm{mL}$ chloramphenicol (both from Sigma-Aldrich, St. Louis, USA), respectively. H. pylori were grown for 2 days at $37{ }^{\circ} \mathrm{C}$ under microaerophilic conditions in AnaeroJars ${ }^{\mathrm{TM}}$ (Oxoid, Wesel, Germany) using Oxoid $^{\mathrm{TM}}$ CampyGen ${ }^{\mathrm{TM}} 2.5 \mathrm{~L}$ gas packs. The bacteria were harvested using sterile cotton swabs and were resuspended in BHI medium.

\section{SEAP Reporter Gene Assays}

The reporter cell line HEK-Blue-hTLR9 $\left(\right.$ TLR9 $\left.^{+}\right)$and its corresponding parental cell line HEK-Blue-Null1 were infected by $H$. pylori to activate transcription factor $\mathrm{NF}-\kappa \mathrm{B}$ and alkaline phosphatase-1 (AP-1), which trigger the expression and secretion of secreted embryonic alkaline phosphatase SEAP, which in turn was used as a measure of NF- $\kappa \mathrm{B}$ activity [16]. After infection, $20 \mu \mathrm{L}$ cell culture supernatant (infected vs. non-infected) was mixed with $180 \mu \mathrm{L}$ Quanti-Blue reagent (InvivoGen) and incubated for $30 \mathrm{~min}$ at $37{ }^{\circ} \mathrm{C}$, following the protocol of the manufacturer. The SEAP levels were determined from the $\mathrm{OD}_{620}$ values measured with the Infinite F200 Pro microplate reader (Tecan, Grödig, Austria).

\section{IL-8 ELISA}

The concentration of chemokine IL- 8 secreted by infected and non-infected HEK-Blue reporter cells was determined using the enzyme-linked immunosorbent assay (ELISA) [44]. To this end, $20 \mu \mathrm{L}$ of the cell culture supernatant of the above SEAP reporter assay was analyzed using the IL-8 Human Uncoated ELISA Kit (Invitrogen, \#88-8086). Supernatants from non-infected samples served as negative control.

\section{Western Blotting}

Infected HEK293 and AGS cell lines were harvested using cell scrapers, and heated at $95^{\circ} \mathrm{C}$ for $5 \mathrm{~min}$ in $1 \times$ Laemmli buffer. Separation of proteins by sodium dodecyl sulfate polyacrylamide gel electrophoresis (SDS-PAGE) was performed on gels with 6-10\% polyacrylamide followed by Western blot analysis using ROTI®PVDF membranes (Carl Roth, Karlsruhe, Germany). The membranes were incubated for $1 \mathrm{~h}$ at $20^{\circ} \mathrm{C}$ with TBS-T buffer $(140 \mathrm{mM} \mathrm{NaCl}$, $25 \mathrm{mM}$ Tris- $\mathrm{HCl} \mathrm{pH} 7.4$ and $0.1 \%$ Tween-20) including either $3 \%$ BSA or $5 \%$ skim milk [45] to block non-specific binding sites. For detection, the following antibodies were used: mouse monoclonal antibody to GAPDH was obtained from Santa Cruz Biotechnology (Heidelberg, Germany). Phosphorylated and total CagA proteins were identified by successive probing of the blots with the mouse monoclonal $\alpha$-pan-phosphotyrosine antibody PY99 (Santa Cruz Biotechnology) and rabbit polyclonal antibody against CagA (Austral Biologicals, San Ramon, USA) [46]. Polyvalent horseradish peroxidase (HRP)-coupled secondary goat antibodies were used to detect mouse and rabbit primary antibodies (Thermo Fisher Scientific, Massachusetts, USA). Subsequently, the blots were visualized using the ECL Prime chemiluminescence kit from GE Healthcare as described [47, 48]. 


\section{Statistical Tests}

All data were obtained from experiments performed in triplicate. GraphPad Prism statistical software (version 8.0) was used for all data analyses. All TLR9 activation data were assessed using One-way analysis of variance (ANOVA) followed by Tukey's test. The level of statistical significance was determined by using the following $P$-values: $P \leq 0.05$ $(*), P \leq 0.01(* *), P \leq 0.001(* * *)$ and $P \leq 0.0001(* * *)$.

\section{Results}

\section{Genetic Analysis of $H$. pylori T4SSs and DNA Transfer Related Genes}

Pairwise tBLASTx comparisons and BLASTp searches of the extracted protein sequences showed the presence of genes encoding VirB proteins (VirB2-VirB4; VirB6-VirB11) as well as the VirD4 (TraG) coupling protein in each of the three T4SS-encoding genomic fragments, encoding the cag T4SS, TFS 3 and TFS4 (Fig. 1). In addition to VirB proteins, both TFS 3 and TFS4 contained genes coding for two VirD2 relaxases (R1x1/VirD2 in TFS3, Rlx2/VirD2 in TFS4), two TraG proteins (TraG1 in TFS3 and TraG2 in TFS4) as well as two XerD tyrosine recombinase-like proteins (XerD1 in TFS3 and XerD2 in TFS4). Alignment of three T4SSs revealed that the synteny of the T4SS component genes was conserved, with minor exceptions due to insertion of additional genes in each sequence. In contrast, the virD2, $\operatorname{tra} G$ and $x e r D$ genes of TFS3 and TFS4 were not present in the cagPAI sequence, and order as well as orientation of virD2 and $x e r D$ differed among TFS3 and TFS4 (Fig. 1). We also noted that the TFS4-encoded topoisomerase and VirB4 proteins in strain P12, as well as the TFS3-encoded XerD recombinase are likely not functional due to frameshift mutations. The nomenclature of the corresponding genes in strain P12 is shown in Supplemental Fig. S1. The fourth H. pylori T4SS, the ComB system, was not included in this study because it is a DNA import apparatus and does not contain DNA export factors such as VirD2, VirD4/TraG and XerD enzymes $[8,17]$.

\section{Clinical H. pylori Type-I Strains Activate TLR9, But Not Type-II Isolates}

To investigate if a collection of different clinical $H$. pylori type-I (cagPAI-positive) and type-II (cagPAI-negative) isolates can activate TLR9, we performed infections of the HEK293 epithelial reporter cell system. Parallel infection of gastric epithelial AGS cells confirmed that type-I (but not type-II) H. pylori strains express a functional $\mathrm{cag}$ T4SS and exhibit comparable CagA expression and phosphorylation levels (Figs. 2A, S2). The HEK293 parental control wild-type (wt) cells that were previously reported to be naturally devoid of expressing most of the known innate immune receptors such as TLRs, thus reducing background NF-кB activation by $H$. pylori to a minimum [49], were used in the corresponding reporter assays. The HEK293 cells were stably transfected with two constructs, human TLR9 $\left(\right.$ TLR9 $^{+}$) and SEAP (secreted embryonic alkaline phosphatase), which allowed to monitor the activity of NF- $\mathrm{\kappa B}$, a major downstream pro-inflammatory transcription factor $[15,16]$. Our results showed that clinical cag T4SS-positive strains including HPAG1 (Sweden), N6 (France), Ka88 (Germany) and 7.13 (USA) activated NF- $\mathrm{KB}$ in TLR9 ${ }^{+}$cells 8 - to 11 -fold in comparison to the parental SEAP control cells without TLR9 (Fig. 2B). In contrast, cag T4SS-negative isolates including Ka125 (Germany), UH4 (Germany), 1061 (Australia) and SouthAfrica7 (Safr7, South Africa) failed to activate TLR9,

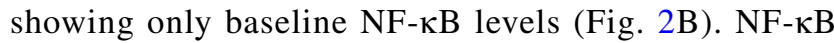

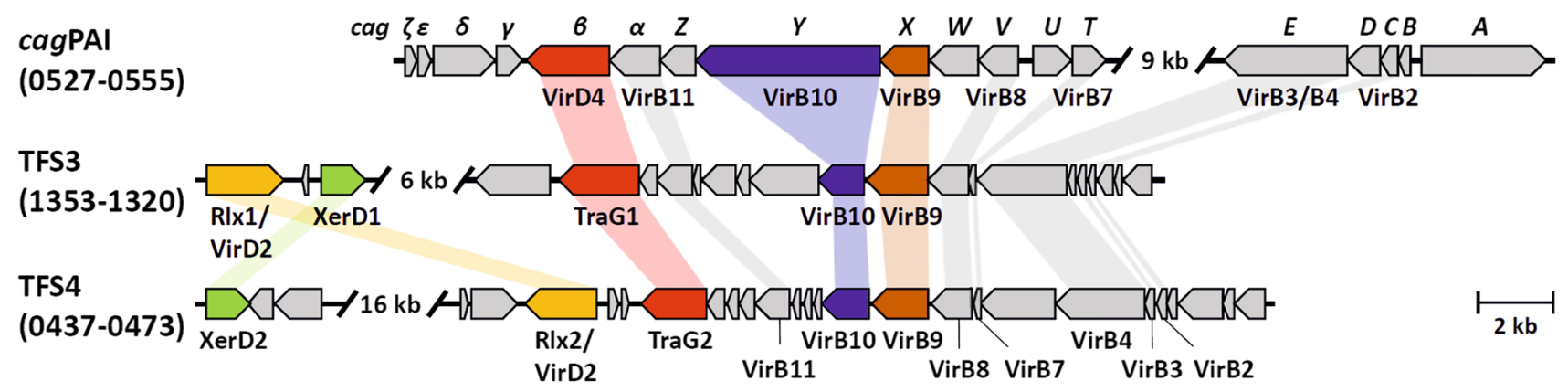

Fig. 1 Genetic composition of three T4SSs in H. pylori strain P12. Conserved structural components VirB2-VirB4 and VirB7-VirB11 of the T4SSs, as well as DNA coupling proteins TraG/VirD4, DNA relaxases R1x/VirD2 and recombinase XerD are highlighted. The TFS3 and TFS4 VirB6 proteins are located within the blanked out regions, in the cagPAI VirB6 is represented by CagW. The P12 locus tag numbers are indicated next to the T4SS. The fourth $H$. pylori T4SS (the ComB system) was not included in this alignment, because it facilitates the import of free DNA, which was not subject of this study 
A

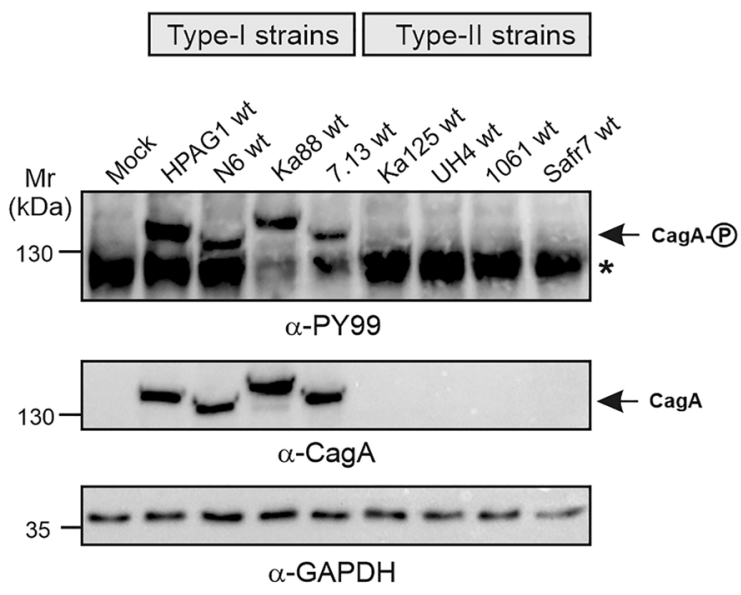

B

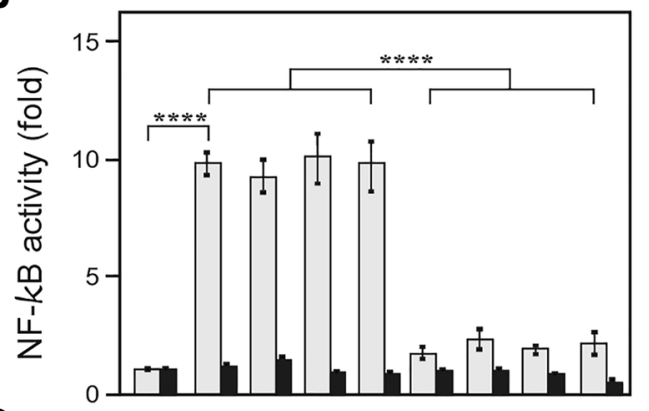

C

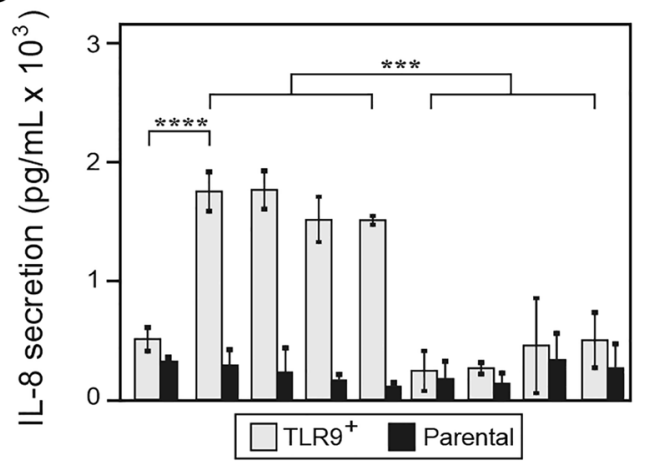

Fig. 2 Stimulation of TLR9 activation by T4SS-positive type-I $H$. pylori strains. A Infection of AGS cells with various $H$. pylori wt strains. In contrast to type-II strains, type-I $H$. pylori isolates express a functional T4SS that enables injection and subsequent phosphorylation of CagA in the cytoplasm. CagA phosphorylation and expression was monitored by Western blot analysis of corresponding protein lysates using antibodies against PY99 and CagA. The asterisk in panel $\mathbf{A}$ indicates an unidentified phosphorylated $125 \mathrm{kDa}$ protein of the host cell. GADPH was used as loading control. B Quantification of TLR9 activation by the SEAP reporter assay. C IL-8 secretion measured by ELISA. Quantitative data are presented as means \pm SD. Safr7: SouthAfrica7

activation via TLR9 correlated with elevated secretion of chemokine IL-8 in the same experiments (Fig. 2C). These results confirm that the cagPAI is required for profound TLR9 stimulation by H. pylori.
A

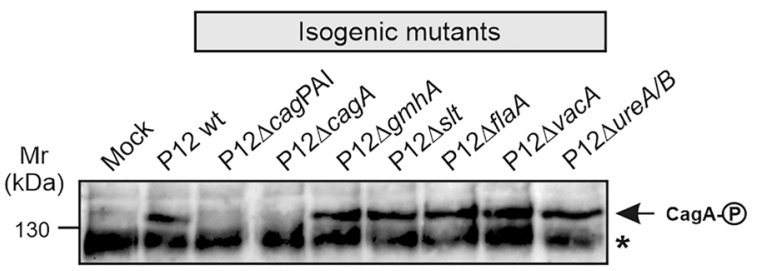

$\alpha-P Y 99$

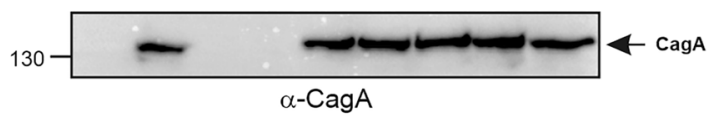

B
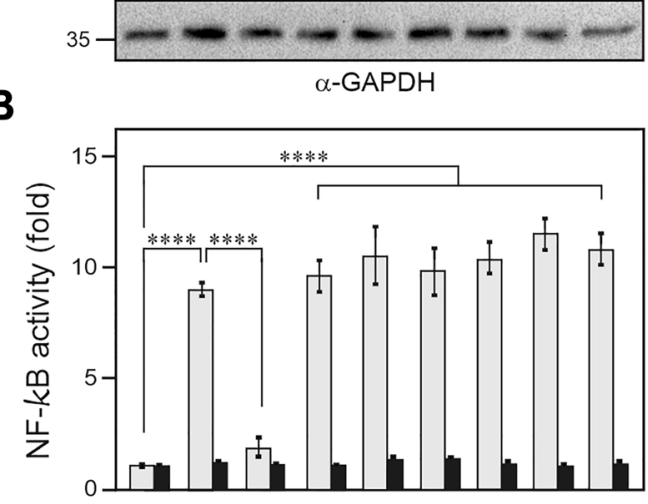

C

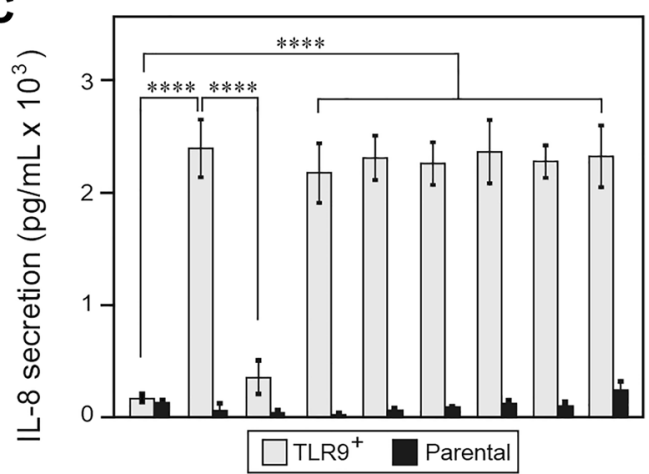

Fig. 3 TLR9 activation by $H$. pylori requires the cagPAI, but not CagA, ADP-heptose or peptidoglycan effector molecules. A Infection of AGS cells with the parental wt strain P12 and isogenic mutants. Western blots of corresponding protein lysates were analyzed with the antibodies shown in the panel. $\alpha$-PY99: phosphorylated CagA; $\alpha$-CagA: total CagA; $\alpha$-GAPDH: loading control. The asterisk in panel A indicates an unidentified phosphorylated $125 \mathrm{kDa}$ protein of the host cell. B Quantification of TLR9 activation by the SEAP reporter assay. C IL-8 secretion measured by ELISA. Quantitative data are presented as means $\pm \mathrm{SD}$

\section{TLR9 Activation by H. pylori Depends on the cagPAI, But Not on Known T4SS Effector Molecules}

In the following experiments, these TLR9 reporter cells were infected with multiple isogenic mutants of well-established H. pylori virulence factors in comparison to the parental wt control (Table S1). As expected, infection of the gastric AGS cells revealed proper CagA expression and phosphorylation (Figs. 3A, S3). While $\Delta f a A, \Delta v a c A$, and $\Delta u r e A / B$ 
deletion mutants did not affect CagA phosphorylation and TLR9 activation, deletion of the entire cagPAI abolished these responses (Fig. 3B). Interestingly, H. pylori deletion mutants $\Delta c a g A, \Delta g m h A$ and $\Delta$ slt defective in genes encoding known translocated T4SS effector molecules CagA $(\Delta c a g A)$, ADP-heptose $(\Delta g m h A)$ and peptidoglycan $(\Delta s l t)$ also activated CagA phosphorylation (except $\Delta c a g A$ ), TLR9 stimulation (Fig. 3B), and IL-8 secretion (Fig. 3C) like wt H. pylori. Hence, TLR9 activation through the cag T4SS is not coupled to injection of these known effector molecules.

\section{Helicobacter pylori-Mediated TLR9 Activation Does Not Require VirD2 Relaxases, VirD4 Coupling Proteins and XerD Recombinase}

Next, we generated isogenic deletion mutants of structural cag T4SS component genes, $\Delta$ virB 9 and $\Delta v i r B 10$, of virD2 relaxases ( $\Delta r l x 1$ and $\Delta r l x 2$ ), and of virD4 coupling factors ( $\Delta$ virD4 of the cag T4SS and $\Delta \operatorname{traG}$ TFS3/TFS4 double mutant) of $H$. pylori strain P12 (Table S1), and investigated their importance in TLR9 activation by SEAP reporter assays. Parallel infection of the gastric AGS cells showed proper CagA expression and phosphorylation by a subset of strains as expected (Figs. 4A, S4). Interestingly, while inactivation of the structural cag T4SS genes virB9 and virB10 abolished CagA phosphorylation and TLR9 activation, inactivation of $r l x 1, r l \times 2$ or $t r a G 1 / 2$ did not affect CagA phosphorylation and activated TLR9 (Fig. 4B) and IL-8 secretion (Fig. 4C) like wt H. pylori. An exception is virD4, which is required for $\mathrm{Cag} \mathrm{A}$ phosphorylation and the corresponding mutant activated TLR9 like wt $H$. pylori (Fig. 4B). Given that the TFS4 genetic island is capable of self-excision and can be transferred between strains by a conjugationlike process facilitated by a XerD tyrosine recombinase [21], we also analyzed an isogenic $x e r D$ knockout mutant ( $\triangle$ xerD2) in TFS4. Note, that xerD1 in TFS3 (locus_tag BPP12_1351) is likely not functional due to a frameshift mutation (Table 1). However, this $\Delta x e r D 2$ knockout strain also stimulated CagA phosphorylation and TLR9 activation during infection (Fig. 4A, B). Thus, our results indicate that all previously reported $H$. pylori relaxases and coupling proteins as well as XerD recombinases that are involved in DNA transfer by canonical T4SSs play no role in TLR9 activation by $H$. pylori.

\section{TLR9 Activation and Role of T4SS Genes During Infection with Worldwide Clinical H. pylori Strains}

The results obtained above with isogenic T4SS mutants of strain P12 were surprising. To corroborate these findings, HEK-Blue-hTLR9 reporter cells were infected with several clinical wt $H$. pylori isolates of worldwide origin, for which full genome sequences are available (Table 1).
A
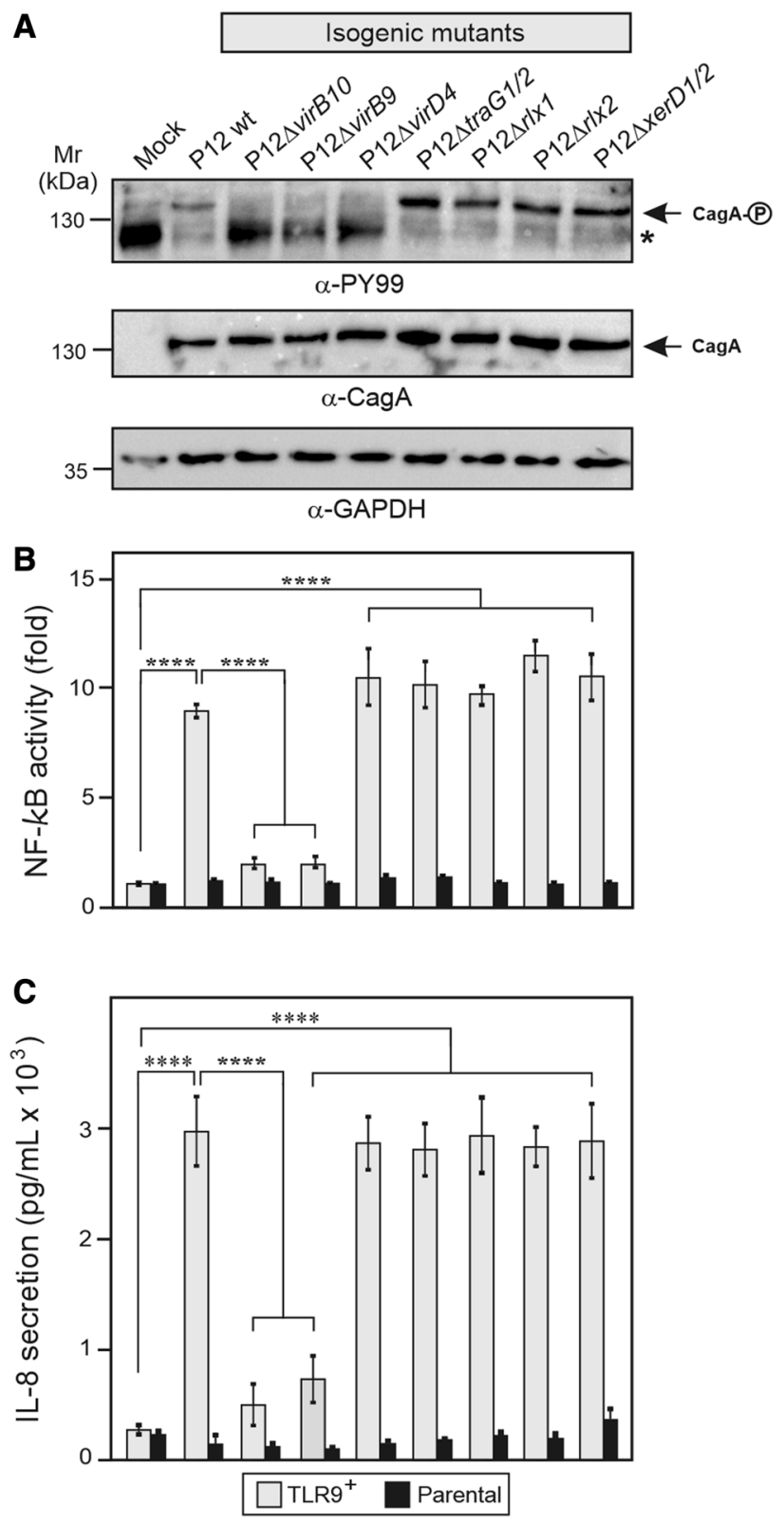

Fig. 4 TLR9 activation by H. pylori does not involve VirD2 relaxases, VirD4 coupling proteins or XerD recombinase. A Infection of AGS cells with the parental wt strain P12 and isogenic mutants. Western blots of corresponding protein lysates were analyzed with the antibodies shown in the panel. $\alpha$-PY99: phosphorylated CagA; $\alpha$-CagA: total CagA; $\alpha$-GAPDH: loading control. The asterisk in panel $\mathbf{A}$ indicates an unidentified phosphorylated $125 \mathrm{kDa}$ protein of the host cell. B Quantification of TLR9 activation by the SEAP reporter assay. C IL-8 secretion measured by ELISA. Quantitative data are shown as means \pm SD

The results show that all cag T4SS-positive strains from Gambia (Gam94/24), Germany (P12), Italy (G27), France (N6), Sweden (HPAG1), India (India7), Japan (TN2wt), Australia (NCTC11637, PMSS1), USA (B128, 7.13, J166) and Peru (Sat464, Shi470) activated TLR9, but not the 
Table 1 Presence or absence of T4SS genes encoding coupling protein TraG, relaxase, recombinase/integrase XerD, and cagPAI in worldwide $H$. pylori strains in relation to TLR9 activation

\begin{tabular}{|c|c|c|c|c|c|c|c|c|}
\hline \multirow[t]{4}{*}{ Strain } & \multicolumn{8}{|l|}{ Locus } \\
\hline & \multicolumn{3}{|l|}{ TFS3 } & \multicolumn{3}{|l|}{ TFS4 } & \multirow{3}{*}{$\begin{array}{l}\text { cag T4SS } \\
0527-0555^{\mathrm{a}} \\
\text { cagPAI }\end{array}$} & \multirow{3}{*}{$\begin{array}{l}\text { TLR9 } \\
\text { activa- } \\
\text { tion }\end{array}$} \\
\hline & $1337^{\mathrm{a}}$ & $1353^{\mathrm{a}}$ & $1351^{\mathrm{a}}$ & $0454^{\mathrm{a}}$ & $0451^{\mathrm{a}}$ & $0437^{\mathrm{a}}$ & & \\
\hline & traGl & rlxl & xerD1 & traG2 & $r l x 2$ & xerD2 & & \\
\hline \multicolumn{9}{|l|}{ Europe } \\
\hline $\mathrm{P} 12$ & + & + & $+^{\mathrm{b}}$ & + & + & + & + & + \\
\hline 26695 & - & $+^{\mathrm{c}}$ & + & $+^{\mathrm{c}}$ & $+^{\mathrm{b}}$ & - & + & + \\
\hline N6 & - & $+^{\mathrm{d}}$ & + & + & + & + & + & + \\
\hline G27 & - & - & - & + & + & - & + & + \\
\hline HPAG1 & - & - & - & - & - & - & + & + \\
\hline \multicolumn{9}{|l|}{ Australia } \\
\hline PMSS1 & - & - & - & - & - & - & + & + \\
\hline NCTC11637 & - & $+^{\mathrm{b}}$ & + & + & $t^{\mathrm{b}}$ & + & + & + \\
\hline \multicolumn{9}{|l|}{ USA } \\
\hline B128 & + & $+^{\mathrm{b}}$ & + & - & + & + & + & + \\
\hline 7.13 & + & $+^{\mathrm{b}}$ & + & - & + & + & + & + \\
\hline J166 & + & + & + & - & - & - & + & + \\
\hline \multicolumn{9}{|l|}{ Asia } \\
\hline $\mathrm{TN} 2$ & - & $+^{\mathrm{b}}$ & + & + & + & + & + & + \\
\hline India7 & + & + & + & - & $+^{\mathrm{b}}$ & + & + & + \\
\hline \multicolumn{9}{|l|}{ Peru } \\
\hline Cuz20 & - & - & - & + & + & - & + & + \\
\hline Shi470 & - & - & - & + & + & - & + & + \\
\hline \multicolumn{9}{|l|}{ Africa } \\
\hline Gambia94/24 & $+^{\mathrm{a}}$ & + & + & + & $+^{\mathrm{a}}$ & + & + & + \\
\hline SouthAfrica7 & - & - & - & + & + & + & - & - \\
\hline
\end{tabular}

cag T4SS-negative strain SouthAfrica7. Interestingly, while all of the above TLR9-activating strains possess the known cag T4SS virB/D genes, pairwise genome comparisons revealed that the TFS3 and TFS4 genes are present in some but not all strains (Table 1). For example, strain 7.13 carries traGl and $x e r D 1$ (TFS3) as well as $r l \times 2$ and xerD2 genes (TFS4), but $r l x 1$ (TFS3) and traG2 (TFS4) are missing. In G27, the TFS3 genes are entirely missing and $x e r D 2$ is absent in TFS4. In 26695, the traG genes are either missing (traGl, TFS3) or non-functional due to insertion of an IS element (traG2, TFS4). Most remarkably, while strains PMSS1 and HPAG1 do not possess any of the analyzed TFS3 and TFS4 genes, the two strains strongly activated TLR9 (Table 1). Thus, these data confirmed that the proposed DNA transfer enzymes VirD2 (R1x1 and R1x2), TraG (TraG1 and TraG2) and XerD
(XerD1 and XerD2) encoded on the TFS3 and TFS4 gene clusters play no role in TLR9 activation by H. pylori.

\section{Discussion}

TLRs represent an important group of pathogen recognition receptors (PRRs), which detect microbial structures that are evolutionarily conserved (reviewed in [37-39, 50]). For a long time, H. pylori was thought to avoid immune recognition by TLRs, mainly due to the poor stimulatory activity of its lipopolysaccharide (LPS) and flagellin (reviewed in [49, 51-53]). However, more recent studies indicated that $H$. pylori activates two important TLRs, TLR5 [35, 36] and TLR9 [15, 16], in a T4SS-dependent manner, that facilitate the detection of $H$. pylori by its 
host [35, 52-54]. While TLR5 is stimulated by the interaction with two structural elements of the cag T4SS pilus, CagL and CagY, TLR9 has been reported to be activated by translocated chromosomal $H$. pylori DNA as shown by fluorescence microscopy in HEK293-TLR9 reporter cells [16]. TLR9 represents an intracellular PRR, which is predominantly expressed in the cytoplasm of macrophages, dendritic cells and specific antigen-presenting cells as well as cancer cells (reviewed in $[38,39]$ ). The primary ligand of TLR9 is hypo-methylated CpG DNA originating from microbes, and this interaction commonly triggers inflammatory signal transduction events via type-I interferons and pro-inflammatory cytokines produced through transcription factor NF- $\mathrm{KB}$, which finally results in the engulfment and killing of intruding pathogens (reviewed in [38, 39]). Remarkably, H. pylori-infected $\mathrm{Tlr} 9^{-/-}$knockout mice obtained significantly stronger inflammation scores in comparison to infected wt mice [15]. At the molecular level, gastric mucosal titers of IL-17 were largely upregulated in infected $\mathrm{Tlr} 9^{-/-}$knockout mice compared with infected wt mice, but not typical $\mathrm{T}_{\mathrm{H}} 1$ or $\mathrm{T}_{\mathrm{H}} 2$ cytokines [15]. In agreement with these observations, infection of IL-17A ${ }^{-/-}$knockout mice by $H$. pylori resulted in reduced levels of gastritis compared to wt mice. All these activities in mice were clearly cagPAI-dependent. Together, it appears that $H$. pylori employs its cag T4SS and TLR9 to modulate the host immune responses, probably to ensure persistent infection [51]. On the other hand, TLR9 may also be involved in cancer development, as various reports demonstrated that TLR9 activity is associated with enhanced malignancy, and it impacts assorted immune activities against cancer (reviewed in [38, 39]). However, the underlying mechanisms that define the role of TLR9 in the onset and progression of $H$. pylori-triggered gastric cancer are not entirely understood and need to be unraveled in further studies.

Conjugation in bacteria represents T4SS-mediated transfer of DNA between many bacterial species, and also facilitates delivery of DNA from bacteria into eukaryotic target cells upon infection $[9,10]$. Canonical T4SSs involved in this conjugational DNA transfer typically consist of two major elements, the DNA transfer and replication system (called Dtr) and the mating pair formation system (named Mpf), following the characteristic "replication and secretion" scheme (reviewed in $[7,9,10,55,56])$. The $\mathrm{Mpf}$ system is basically composed of the above described 11 membrane-spanning VirB or Tra proteins, which translocate substrates across the membranes and form an extracellular pilus $[9,10]$. In addition, the Dtr comprises the initiation complex of conjugative DNA transfer, called the relaxosome. The driving factor is the relaxase or VirD2 protein, which is commonly loaded onto the origin of transfer (oriT) by accessory DNA-binding proteins [57]. The VirD2 enzyme (relaxase) then cleaves a phosphodiester bond at the nicking site in one strand of the oriT, and covalently binds to the 5'end of the cleaved DNA strand. Subsequently, the single-stranded DNA is translocated, which is mediated by an adapted rolling-circle replication mechanism [57]. Thus, the substrate DNA of conjugative T4SSs is always exported as a DNA-protein complex of the relaxase VirD2 with single-stranded DNA, but not as naked DNA. After the circle of transfer is completed, the process is terminated by the cleaving-joining activity of the relaxase. Another critical factor for conjugative DNA transfer is the so-called coupling protein, shown to bridge the Dtr with the Mpf by specific interactions. The best investigated coupling factors are VirD4 (from the T-DNA transfer system of the tumor inducing (Ti) plasmid in A. tumefaciens) and TraG (from the IncP1 plasmid RP4) (reviewed in $[9,10,55,56])$. These proteins exhibit NTPase activity and were reported to form a pore via oligomerization and bind DNA without sequence specificity. Remarkably, H. pylori encodes a VirD4 ortholog in the cag T4SS, and two TraG-like proteins as well as two VirD2 relaxase proteins in TFS3 and TFS4, respectively (Fig. 1). We therefore proposed that these enzymes may be interchangeable among the T4SSs and could be involved in the proposed H. pylori DNA transfer and TLR9 activation by the $c a g$ PAI. However, while knockout of the structural cag T4SS genes virB9 and virB10 abolished TLR9 activation by $H$. pylori, in good agreement with previous studies $[15,16]$, inactivation of $r l x 1, r l x 2$, cag 5 and $\operatorname{traG} 1 / 2 \mathrm{did}$ not affect the activation of TLR9. These deletion mutants activated TLR9 similar to their parental wt bacteria. In addition, knockout of $x e r D$ genes in TFS3 and TFS4, encoding a tyrosine recombinase with reported function in horizontal DNA transfer by a conjugation-like mechanism between $H$. pylori strains [21], is also not involved in TLR9 activation by $H$. pylori. Thus, we are obviously facing a remarkable paradox. Our present findings therefore suggest the presence of a previously unknown T4SS-dependent mechanism of TLR9 activation by $H$. pylori. Since a conjugative T4SSdependent DNA export without involvement of a relaxasome and a DNA coupling factor is so far unknown, the exact mechanism of DNA transfer by $H$. pylori and involved DNA processing/guiding enzymes etc. still remain mysterious, and need to be studied in detail in future research.

\section{Conclusion}

The H. pylori cag T4SS was previously reported to play a role in conjugative transfer of chromosomal bacterial DNA into the host cell cytoplasm, where the injected $H$. pylori DNA activates TLR9 [15, 16, 51, 52, 54]. Canonical DNAdelivering T4SSs in numerous bacteria are comprised of structural VirB proteins, VirD2 relaxase as well as VirD4/ 
TraG coupling proteins that mediate DNA processing and guiding of the covalently bound DNA through the T4SS channel. However, our data show that neither of the previously suspected proteins VirD2, TraG, or recombinase XerD are involved in TLR9 activation by $H$. pylori. Thus, our data suggest the presence of a novel, unique non-canonical cag T4SS-dependent mechanism of TLR9 activation by H. pylori that is independent of VirD2, TraG and XerD proteins.

Supplementary Information The online version contains supplementary material available at https://doi.org/10.1007/s00284-022-02813-9.

Acknowledgements Nina Rottmann and Wilhelm Brill are acknowledged for excellent technical assistance. We thank Drs. Agnes Labigne, Antonello Covacci, Douglas Berg, Richard Peek jr., Lars Engstrand, and Adrian Lee for providing various $H$. pylori wt strains, and Wolfgang Fischer for the $x e r D 2$ knockout strain.

Author Contributions All authors checked the work at the various progress stages and certified the final paper. SB and NT conceptualized the study and supervised the technicians. NT carried out the majority of the cloning studies, $H$. pylori mutagenesis, sequencing and infection experiments. BL performed the bioinformatics and the genetic analyses of T4SSs. YY contributed strains and tools. SB critically evaluated the data and wrote the manuscript. BL, YY and NT reviewed and made final changes to the last version of the manuscript.

Funding Open Access funding enabled and organized by Projekt DEAL. We acknowledge the support by Friedrich-Alexander-Universität Erlangen-Nürnberg (FAU) within the funding program Open Access Publishing. The work of N.T. was funded by the Deutsche Forschungsgemeinschaft (DFG), Grant Number TE776/3-1.

Data Availability All data are available.

Code Availability Not applicable.

\section{Declarations}

Conflict of interest The authors have no conflict of interest to declare.

Consent to Participate All authors were included in the work, see Author contributions.

\section{Consent for Publication Open access.}

Ethical approval Not applicable.

Open Access This article is licensed under a Creative Commons Attribution 4.0 International License, which permits use, sharing, adaptation, distribution and reproduction in any medium or format, as long as you give appropriate credit to the original author(s) and the source, provide a link to the Creative Commons licence, and indicate if changes were made. The images or other third party material in this article are included in the article's Creative Commons licence, unless indicated otherwise in a credit line to the material. If material is not included in the article's Creative Commons licence and your intended use is not permitted by statutory regulation or exceeds the permitted use, you will need to obtain permission directly from the copyright holder. To view a copy of this licence, visit http://creativecommons.org/licenses/by/4.0/.

\section{References}

1. Salama NR, Hartung ML, Muller A (2013) Life in the human stomach: persistence strategies of the bacterial pathogen Helicobacter pylori. Nat Rev Microbiol 11:385-399

2. Amieva M, Peek RM (2016) Pathobiology of Helicobacter pyloriinduced gastric cancer. Gastroenterology 150:64-78

3. Sung H, Ferlay J, Siegel RL, Laversanne M, Soerjomataram I, Jemal A, Bray F (2021) Global cancer statistics 2020: GLOBOCAN estimates of incidence and mortality worldwide for 36 cancers in 185 countries. CA Cancer J Clin 71:209-249

4. Rudnicka K, Backert S, Chmiela M (2019) Genetic polymorphisms in inflammatory and other regulators in gastric cancer: risks and clinical consequences. Curr Top Microbiol Immunol 421:53-76

5. Linz B, Balloux F, Moodley Y, Manica A, Liu H, Roumagnac P, Falush D, Stamer C, Prugnolle F, van der Merwe SW, Yamaoka Y, Graham DY, Perez-Trallero E, Wadstrom T, Suerbaum S, Achtman M (2007) An African origin for the intimate association between humans and Helicobacter pylori. Nature 445:915-918

6. Moodley Y, Linz B, Bond RP, Nieuwoudt M, Soodyall H, Schlebusch CM, Bernhoft S, Hale J, Suerbaum S, Mugisha L, van der Merwe SW, Achtman M (2012) Age of the association between Helicobacter pylori and man. PLoS Pathog 8:e1002693

7. Fernandez-Gonzalez E, Backert S (2014) DNA transfer in the gastric pathogen Helicobacter pylori. J Gastroenterol 49:594-604

8. Fischer W, Tegtmeyer N, Stingl K, Backert S (2020) Four chromosomal type IV secretion systems in Helicobacter pylori: composition, structure and function. Front Microbiol 11:1592

9. Grohmann E, Christie PJ, Waksman G, Backert S (2018) Type IV secretion in Gram-negative and Gram-positive bacteria. Mol Microbiol 107:455-471

10. Costa TRD, Harb L, Khara P, Zeng L, Hu B, Christie PJ (2021) Type IV secretion systems: advances in structure, function, and activation. Mol Microbiol 115:436-452

11. Delahay RM, Croxall NJ, Stephens AD (2018) Phylogeographic diversity and mosaicism of the Helicobacter pylori tfs integrative and conjugative elements. Mob DNA 9:5

12. Tegtmeyer N, Neddermann M, Asche CI, Backert S (2017) Subversion of host kinases: a key network in cellular signaling hijacked by Helicobacter pylori CagA. Mol Microbiol 105:358-372

13. Pfannkuch L, Hurwitz R, Traulsen J, Sigulla J, Poeschke M, Matzner L, Kosma P, Schmid M, Meyer TF (2019) ADP heptose, a novel pathogen-associated molecular pattern identified in Helicobacter pylori. FASEB J 33:9087-9099

14. Viala J, Chaput C, Boneca IG, Cardona A, Girardin SE, Moran AP, Athman R, Memet S, Huerre MR, Coyle AJ, DiStefano PS, Sansonetti PJ, Labigne A, Bertin J, Philpott DJ, Ferrero RL (2004) Nod1 responds to peptidoglycan delivered by the Helicobacter pylori cag pathogenicity island. Nat Immunol 5:1166-1174

15. Varga MG, Piazuelo MB, Romero-Gallo J, Delgado AG, Suarez G, Whitaker ME, Krishna US, Patel RV, Skaar EP, Wilson KT, Algood HM, Peek RM Jr (2016) TLR9 activation suppresses inflammation in response to Helicobacter pylori infection. Am J Physiol Gastrointest Liver Physiol 311:G852-G858

16. Varga MG, Shaffer CL, Sierra JC, Suarez G, Piazuelo MB, Whitaker ME, Romero-Gallo J, Krishna US, Delgado A, Gomez MA, Good JA, Almqvist F, Skaar EP, Correa P, Wilson KT, Hadjifrangiskou M, Peek RM (2016) Pathogenic Helicobacter pylori strains translocate DNA and activate TLR9 via the cancer-associated cag type IV secretion system. Oncogene 35:6262-6269

17. Hofreuter D, Odenbreit S, Haas R (2001) Natural transformation competence in Helicobacter pylori is mediated by the basic components of a type IV secretion system. Mol Microbiol 41:379-391 
18. Backert S, Von Nickisch-Rosenegk E, Meyer TF (1998) Potential role of two Helicobacter pylori relaxases in DNA transfer? Mol Microbiol 30:673-674

19. Backert S, Kwok T, König W (2005) Conjugative plasmid DNA transfer in Helicobacter pylori mediated by chromosomally encoded relaxase and TraG-like proteins. Microbiology (Reading) 151:3493-3503

20. Grove JI, Alandiyjany MN, Delahay RM (2013) Site-specific relaxase activity of a VirD2-like protein encoded within the $t f_{S} 4$ genomic island of Helicobacter pylori. J Biol Chem 288:26385-26396

21. Fischer W, Windhager L, Rohrer S, Zeiller M, Karnholz A, Hoffmann R, Zimmer R, Haas R (2010) Strain-specific genes of Helicobacter pylori: genome evolution driven by a novel type IV secretion system and genomic island transfer. Nucleic Acids Res 38:6089-6101

22. Kim DJ, Park KS, Kim JH, Yang SH, Yoon JY, Han BG, Kim HS, Lee SJ, Jang JY, Kim KH, Kim MJ, Song JS, Kim HJ, Park CM, Lee SK, Lee BI, Suh SW (2010) Helicobacter pylori proinflammatory protein up-regulates NF-kappaB as a cell-translocating Ser/Thr kinase. Proc Natl Acad Sci USA 107:21418-21423

23. Tenguria S, Ansari SA, Khan N, Ranjan A, Devi S, Tegtmeyer N, Lind J, Backert S, Ahmed N (2014) Helicobacter pylori cell translocating kinase (CtkA/JHP0940) is pro-apoptotic in mouse macrophages and acts as auto-phosphorylating tyrosine kinase. Int J Med Microbiol 304:1066-1076

24. Alandiyjany MN, Croxall NJ, Grove JI, Delahay RM (2017) A role for the $t f s 3$ ICE-encoded type IV secretion system in proinflammatory signalling by the Helicobacter pylori Ser/Thr kinase, CtkA. PLoS ONE 12:0182144

25. Fischer W, Puls J, Buhrdorf R, Gebert B, Odenbreit S, Haas R (2001) Systematic mutagenesis of the Helicobacter pylori cag pathogenicity island: essential genes for CagA translocation in host cells and induction of interleukin-8. Mol Microbiol 42:1337-1348

26. Olbermann P, Josenhans C, Moodley Y, Uhr M, Stamer C, Vauterin M, Suerbaum S, Achtman M, Linz B (2010) A global overview of the genetic and functional diversity in the Helicobacter pylori cag pathogenicity island. PLoS Genet 6:e1001069

27. Akopyants NS, Clifton SW, Kersulyte D, Crabtree JE, Youree BE, Reece CA, Bukanov NO, Drazek ES, Roe BA, Berg DE (1998) Analyses of the cag pathogenicity island of Helicobacter pylori. Mol Microbiol 28:37-53

28. Censini S, Lange C, Xiang Z, Crabtree JE, Ghiara P, Borodovsky M, Rappuoli R, Covacci A (1996) cag, a pathogenicity island of Helicobacter pylori, encodes type I-specific and disease-associated virulence factors. Proc Natl Acad Sci USA 93:14648-14653

29. Frick-Cheng AE, Pyburn TM, Voss BJ, McDonald WH, Ohi MD, Cover TL (2016) Molecular and structural analysis of the Helicobacter pylori cag type IV secretion system core complex. MBio 7:e2001-15. https://doi.org/10.1128/mBio.02001-15

30. Chung JM, Sheedlo MJ, Campbell AM, Sawhney N, Frick-Cheng AE, Lacy DB, Cover TL, Ohi MD (2019) Structure of the Helicobacter pylori Cag type IV secretion system. Elife 8:e47644. https://doi.org/10.7554/eLife.47644

31. Kwok T, Zabler D, Urman S, Rohde M, Hartig R, Wessler S, Misselwitz R, Berger J, Sewald N, König W, Backert S (2007) Helicobacter exploits integrin for type IV secretion and kinase activation. Nature 449:862-866

32. Buss M, Tegtmeyer N, Schnieder J, Dong X, Li J, Springer TA, Backert S, Niemann HH (2019) Specific high affinity interaction of Helicobacter pylori CagL with integrin alphaV beta6 promotes type IV secretion of CagA into human cells. FEBS J 286:3980-3997

33. Tegtmeyer N, Backert S (2020) Different roles of integrin-beta1 and integrin-alphav for type IV secretion of CagA versus cell elongation phenotype and cell lifting by Helicobacter pylori. PLoS Pathog 16:e1008135

34. Backert S, Tegtmeyer N (2017) Type IV secretion and signal transduction of Helicobacter pylori CagA through interactions with host cell receptors. Toxins (Basel) 9:115. https://doi.org/10. 3390/toxins9040115

35. Pachathundikandi SK, Tegtmeyer N, Arnold IC, Lind J, Neddermann M, Falkeis-Veits C, Chattopadhyay S, Bronstrup M, Tegge W, Hong M, Sticht H, Vieth M, Muller A, Backert S (2019) T4SSdependent TLR5 activation by Helicobacter pylori infection. Nat Commun 10:5717

36. Tegtmeyer N, Neddermann M, Lind J, Pachathundikandi SK, Sharafutdinov I, Gutierrez-Escobar AJ, Bronstrup M, Tegge W, Hong M, Rohde M, Delahay RM, Vieth M, Sticht H, Backert S (2020) Toll-like receptor 5 activation by the CagY repeat domains of Helicobacter pylori. Cell Rep 32:108159

37. Fukata M, Abreu MT (2008) Role of toll-like receptors in gastrointestinal malignancies. Oncogene 27:234-243

38. Alzahrani B (2020) The biology of toll-like receptor 9 and its role in cancer. Crit Rev Eukaryot Gene Expr 30:457-474

39. Karapetyan L, Luke JJ, Davar D (2020) Toll-like receptor 9 agonists in cancer. Onco Targets Ther 13:10039-10060

40. Carver T, Berriman M, Tivey A, Patel C, Bohme U, Barrell BG, Parkhill J, Rajandream MA (2008) Artemis and ACT: viewing, annotating and comparing sequences stored in a relational database. Bioinformatics 24:2672-2676

41. Conradi J, Huber S, Gaus K, Mertink F, Royo Gracia S, Strijowski U, Backert S, Sewald N (2012) Cyclic RGD peptides interfere with binding of the Helicobacter pylori protein CagL to integrins alphaVbeta3 and alpha5beta1. Amino Acids 43:219-232

42. Blumenthal B, Hoffmann C, Aktories K, Backert S, Schmidt G (2007) The cytotoxic necrotizing factors from Yersinia pseudotuberculosis and from Escherichia coli bind to different cellular receptors but take the same route to the cytosol. Infect Immun 75:3344-3353

43. Moese S, Selbach M, Zimny-Arndt U, Jungblut PR, Meyer TF, Backert S (2001) Identification of a tyrosine-phosphorylated 35 $\mathrm{kDa}$ carboxy-terminal fragment (p35CagA) of the Helicobacter pylori CagA protein in phagocytic cells: processing or breakage? Proteomics 1:618-629

44. Heimesaat MM, Alutis M, Grundmann U, Fischer A, Tegtmeyer N, Böhm M, Kühl AA, Göbel UB, Backert S, Bereswill S (2014) The role of serine protease HtrA in acute ulcerative enterocolitis and extra-intestinal immune responses during Campylobacter jejuni infection of gnotobiotic IL-10 deficient mice. Front Cell Infect Microbiol 4:77

45. Tegtmeyer N, Moodley Y, Yamaoka Y, Pernitzsch SR, Schmidt V, Traverso FR, Schmidt TP, Rad R, Yeoh KG, Bow H, Torres J, Gerhard M, Schneider G, Wessler S, Backert S (2016) Characterisation of worldwide Helicobacter pylori strains reveals genetic conservation and essentiality of serine protease HtrA. Mol Microbiol 99:925-944

46. Backert S, Moese S, Selbach M, Brinkmann V, Meyer TF (2001) Phosphorylation of tyrosine 972 of the Helicobacter pylori CagA protein is essential for induction of a scattering phenotype in gastric epithelial cells. Mol Microbiol 42:631-644

47. Schmidt TP, Perna AM, Fugmann T, Bohm M, Hiss J, Haller S, Gotz C, Tegtmeyer N, Hoy B, Rau TT, Neri D, Backert S, Schneider G, Wessler S (2016) Identification of E-cadherin signature motifs functioning as cleavage sites for Helicobacter pylori $\mathrm{HtrA}$. Sci Rep 6:23264

48. Boehm M, Krause-Gruszczynska M, Rohde M, Tegtmeyer N, Takahashi S, Oyarzabal OA, Backert S (2011) Major host factors involved in epithelial cell invasion of Campylobacter jejuni: role 
of fibronectin, integrin beta1, FAK, Tiam-1, and DOCK180 in activating Rho GTPase Rac1. Front Cell Infect Microbiol 1:17

49. Pachathundikandi SK, Lind J, Tegtmeyer N, El-Omar EM, Backert S (2015) Interplay of the gastric pathogen Helicobacter pylori with toll-like receptors. Biomed Res Int. https://doi.org/10.1155/ 2015/192420

50. Castano-Rodriguez N, Kaakoush NO, Mitchell HM (2014) Pattern-recognition receptors and gastric cancer. Front Immunol 5:336

51. Varga MG, Peek RM (2017) DNA transfer and Toll-like receptor modulation by Helicobacter pylori. Curr Top Microbiol Immunol 400:169-193

52. Rad R, Ballhorn W, Voland P, Eisenacher K, Mages J, Rad L, Ferstl R, Lang R, Wagner H, Schmid RM, Bauer S, Prinz C, Kirschning CJ, Krug A (2009) Extracellular and intracellular pattern recognition receptors cooperate in the recognition of Helicobacter pylori. Gastroenterology 136:2247-2257

53. Pachathundikandi SK, Tegtmeyer N, Backert S (2013) Signal transduction of Helicobacter pylori during interaction with host cell protein receptors of epithelial and immune cells. Gut Microbes 4:454-474

54. Lin AS, Dooyema SDR, Frick-Cheng AE, Harvey ML, Suarez G, Loh JT, McDonald WH, McClain MS, Peek RM Jr, Cover TL
(2020) Bacterial energetic requirements for Helicobacter pylori Cag type IV secretion system-dependent alterations in gastric epithelial cells. Infect Immun 88:e0790-19. https://doi.org/10.1128/ IAI.00790-19

55. Llosa M, Gomis-Ruth FX, Coll M, de la Cruz FdF (2002) Bacterial conjugation: a two-step mechanism for DNA transport. Mol Microbiol 45:1-8

56. Schroder G, Krause S, Zechner EL, Traxler B, Yeo HJ, Lurz R, Waksman G, Lanka E (2002) TraG-like proteins of DNA transfer systems and of the Helicobacter pylori type IV secretion system: inner membrane gate for exported substrates? J Bacteriol 184:2767-2779

57. Lanka E, Wilkins BM (1995) DNA processing reactions in bacterial conjugation. Annu Rev Biochem 64:141-169

Publisher's Note Springer Nature remains neutral with regard to jurisdictional claims in published maps and institutional affiliations. 